\title{
Rewarding and Aversive Brain Stimulation Opposite Effects on Medial Thalamic Units'
}

\author{
JAMES J. KEENE ${ }^{2}$ AND KENNETH L. CASEY \\ Department of Physiology, University of Michigan Medical School, Ann Arbor, Michigan 48104
}

(Received 31 August 1972)

\begin{abstract}
KEENE, J. J. AND K. L. CASEY. Rewarding and aversive brain stimulation: opposite effects on medial thalamic units. PHYSIOL. BEHAV. 10(2) 283-287, 1973. - Most of the neurons recorded from rat medial thalamus are inhibited by medial forebrain bundle and excited by reticular stimuli delivered at frequencies of $20-60 \mathrm{~Hz}$. These opposite neural responses in single units parallel the opposite behavioral and motivational properties of the brain stimuli and may play a role in integrating reward and pain mechanisms.
\end{abstract}

Brain stimulation Medial thalamus Rewarding Aversive brain stimulation

\begin{abstract}
ANIMALS are frequently confronted with the task of behaving adaptively in the presence of both rewarding and aversive stimuli. A response made under conflicting contingencies of reinforcement is generally influenced by the properties of both of the motivationally opposite stimuli. It is reasonable to suspect that information regarding the rewarding and aversive stimuli converges on, and is integrated by, some population of neurons in the brain. Pertinent to this speculation is the fact that brainstem and midbrain reticular neurons (RET) $[2,11,17]$ and a major system of collaterals from the medial forebrain bundle (MFB) [10] in the lateral hypothalamus both project into medial thalamus [9]. Intracranial stimulation of RET and MFB elicits the motivated behaviors $[4,8,12]$ of escape and selfstimulation respectively. Medial thalamic regions such as the dorsal medial (DM) and paracentral (PC) nuclei have already been implicated in processes of motivation and, more specifically, responsivity to noxious stimuli [3]. As a step toward evaluating the possible behavioral significance of MFB-RET convergence in medial thalamus, this paper reports experiments showing that: (1) MFB and RET stimulation elicits DM and PC unit responses; (2) the populations of DM and PC units affected by MFB and RET stimulation overlap; and, (3) MFB and RET stimulations typically have opposite effects on DM and PC units.
\end{abstract}

\section{METHOD}

The effects of MFB and RET bipolar stimulation on 176 units have been studied with polished tungsten microelectrodes in 13 nembutal anesthetized and 43 unanesthetized postcollicular cerveau isolé rats with artificial maintenance of normal body temperature. In the anesthetized rats, medial thalamic units were recorded during MFB and $\mathrm{n}$. gigantocellularis stimulus treatments. As might be expected from other work [7], the unit responses were sensitive to the depth of anesthesia and were maximal with light anesthesia during which the flexion reflex could be elicited. This consideration led to the use of an unanesthetized cerveau isolé preparation with MFB (Fig. 1A) and midbrain reticular (Fig. 1B) stimulation. With only visual and olfactory sensory inputs remaining, anesthesia was not required. Caudal to the section, the basic respiratory mechanisms remained functional. Unit responses with this preparation were similar to those observed under the best conditions with anesthesia. Sixty additional units were studied in these animals with stimulation of structures near, but outside MFB and RET.

Stimulation parameters were similar to those which elicit motivated behavior: $7-60 \mathrm{~Hz} 0.5 \mathrm{msec}$ pulses at currents up to $600 \mu \mathrm{A}$. A recorded potential was considered to be an action potential of a single neuron when it was all-or-none, stable in amplitude, duration, and wave form under different conditions of stimulation, and clearly isolated from background noise with amplitude from $150 \mu \mathrm{V}$ to several $\mathrm{mV}$. Most units were negative in polarity and had spike durations of approximately $1 \mathrm{msec}$, suggesting that the recordings were from nearby cell bodies rather than axons. Unit responses to successive stimulus pulses in either 7 or $20 \mathrm{~Hz}$ stimulus trains were quantified by a poststimulus histogram generator [18]. A histogram consisted of spike counts over 60 or more stimulus or control trials. Control discharge rates were counted by generating histograms without stimulation. Units showing changes in

\footnotetext{
${ }^{1}$ Supported by NIH Grant NS -06588

${ }^{2}$ Present address: Department of Physiology, University of Puerto Rico Medical Center, Rio Piedras, Puerto Rico 00936
} 


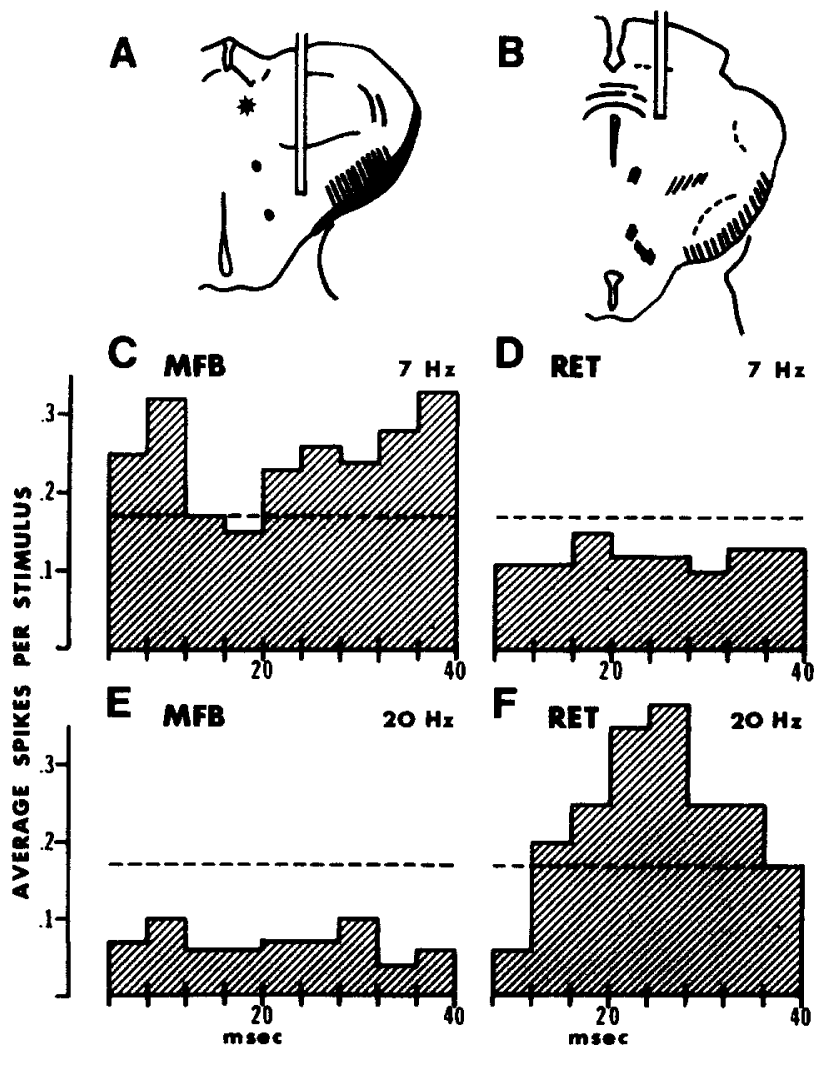

FIG. 1. Opposite effects of MFB (A) and midbrain RET (B) stimulation on a neuron (star in $A$ ) in the dorsal medial nucleus of thalamus. Forty msec poststimulus histograms show that $7 \mathrm{~Hz}$ MFB stimulation increases (C), while $7 \mathrm{~Hz}$ RET decreases (D), the discharge rate with reference to the control rate (dotted line). Changing the frequency of stimuli to $20 \mathrm{~Hz}$ significantly decreases the poststimulus firing with MFB stimulation (E), and increases the discharge rate with RET stimulation $(\mathrm{F})$.

control firing rates between different stimulation treatments were excluded from the analysis.

A unit response was defined as a statistically significant $\left(\mathrm{X}^{2}, p<0.05\right)$ difference in firing rate between the poststimulus and control periods. In order to define excitation and inhibition in a particular post-stimulus period on the basis of extracellular recordings, three parameters were computed for each unit: the control rate, the standard deviation of the control bins, and a $95 \%$ confidence interval around the control rate. Excitation for a particular poststimulus bin is defined as a rate greater than the upper limit of the confidence interval; inhibition is conversely defined (Fig. 2). This method of defining excitation and inhibition is: (1) independent of the unit's control rate; (2) sensitive to variations in the control rate for each unit; and, (3) conservative in its definition of inhibition because the lower limit of the confidence interval is often less than zero for units with low control rates and/or large variations in spontaneous discharge. Finally, this procedure is systematic, objective, and consistent with visual inspection of the unit response on the oscilloscope display. In this paper, the terms excitation and inhibition refer only to increases or decreases in spike rates and do not imply membrane processes which may underly these changes.

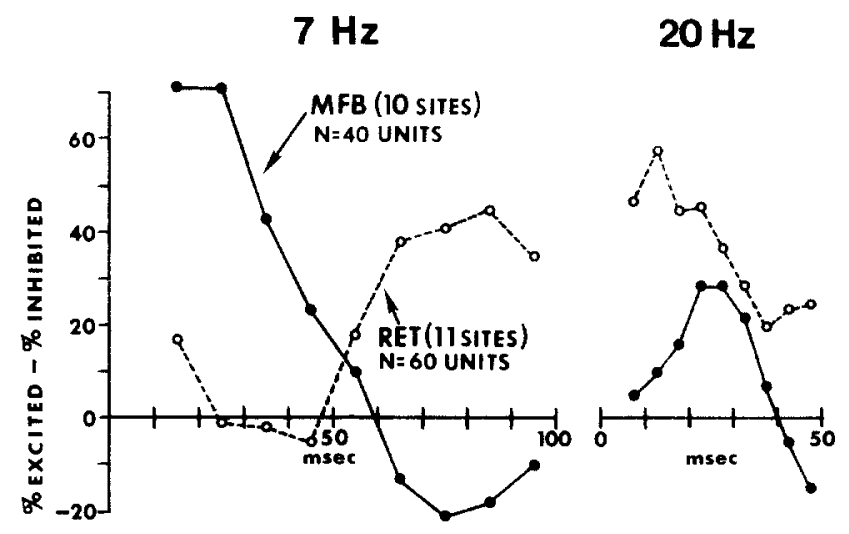

FIG. 2. Opposite MFB and midbrain RET poststimulus and stimulus frequency effects on DM and PC units. For 7 and $20 \mathrm{~Hz}$ stimulation, the percent of units with responses outside a $95 \%$ confidence interval around the cell's control rate was plotted for each poststimulus bin. Each point is the \% excited minus the \% inhibited for that bin and stimulus treatment. $7 \mathrm{~Hz}$ MFB stimuli initially excite and then inhibit DM and PC units. $20 \mathrm{~Hz}$ stimulation reduces the excitation. $7 \mathrm{~Hz}$ RET stimuli typically elicit excitation in the poststimulus period showing MFB inhibition. $20 \mathrm{~Hz}$ stimulation increases the $0-50 \mathrm{msec}$ poststimulus response.

The brains were sliced, mounted on slides, and stained to identify the locations of stimulating electrodes and unit recordings.

\section{RESULTS}

MFB stimulation produces three kinds of responses in the dorsal medial and paracentral nuclei of thalamus.

First. MFB stimulation at $7 \mathrm{~Hz}$ excited 81 of 100 medial thalamic units at latencies as low as $1.2 \mathrm{msec}$. For $40 \mathrm{DM}$ and PC units studied in detail, histogram analysis of the poststimulus periods during $7 \mathrm{~Hz}$ stimulation reveals excitation in the first $50 \mathrm{msec}$ (Fig. $1 \mathrm{C}$ and 2) followed by decreased firing lasting up to $100 \mathrm{msec}$ (Fig. 2). A significant decrease in spike rate in the first $50 \mathrm{msec}$ poststimulus period was never observed with $7 \mathrm{~Hz} \mathrm{MFB}$ stimulation. Excitation usually reappears in the $100 \ldots 150$ msec poststimulus period. This excitation-inhibitionexcitation sequence has a similat time course to the EPSP-IPSP-EPSP patterns that have been frequently recorded in medial thalamus [15] with stimulation that typically elicits slow wave recruiting.

Second. Seven $\mathrm{Hz}$ MFB stimulation elicits medial thalamic slow wave recruiting similar to that seen with low frequency medial thalamic stimulation in cat $[16]$.

Third. In contrast to the $7 \mathrm{~Hz}$ effects, MFB stimulus trains at $60 \mathrm{~Hz}(0.2 \mathrm{sec}$ duration), such as are often used in self-stimulation tests, usually decrease unit discharge for several seconds after stimulus termination (Fig. 3). This has been observed in the acute animals in this study as well as in several chronically implanted, awake rats during selfstimulation behavior [5]. This decrease in discharge rate with higher frequencies of MFB stimulation was quantified by generating poststimulus histograms with 7 and $20 \mathrm{~Hz}$ stimulation for each unit. For 36 of 42 units tested in this manner, $20 \mathrm{~Hz}$ stimulation produced a significant decrease 
$(p>0.05)$ in discharge rate compared to the $7 \mathrm{~Hz}$ rate (Fig. 2). In a subset of these cells tested with lower MFB stimulus currents, the $20 \mathrm{~Hz}$ firing rates were also less than control (Fig. 1E). to $20 \mathrm{~Hz}$ increased $(p<0.005)$ the mean discharge rate from 19 to 45 spikes/sec. Only 2 of $20 \mathrm{DM}$ and PC units studied with 7 and $20 \mathrm{~Hz}$ parafasicular stimulation showed a significant rate increase.
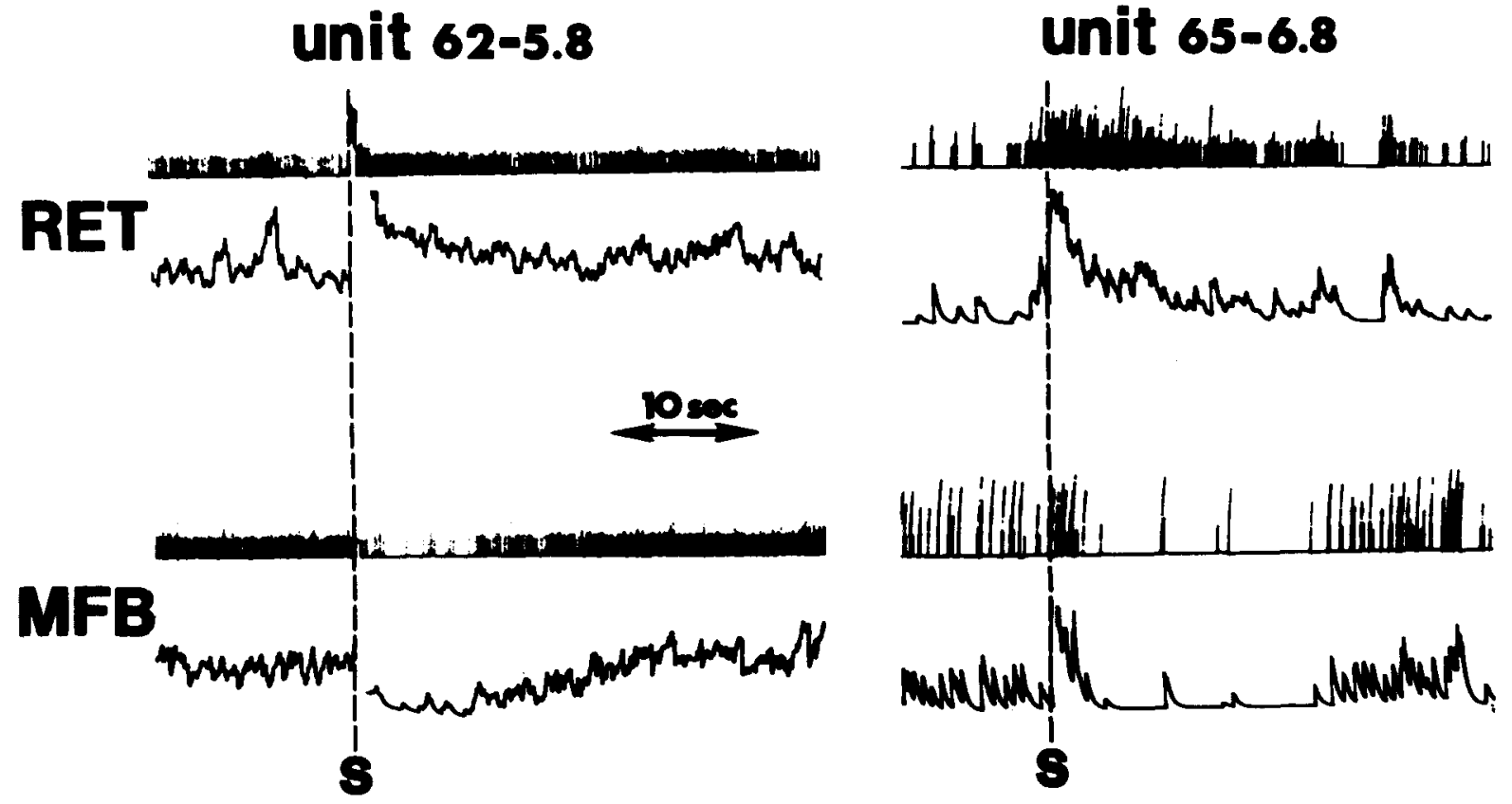

FIG. 3. Opposite changes in posttrain discharge rate with MFB and RET stimulation. Pulses marking the discharge of a single isolated unit (upper records) and their integration representing firing rate (lower records) are shown for a parafasicular unit (62-5.8) and a paracentral unit $(65-6.8)$. For both units, a RET stimulus train $(0.2 \mathrm{sec}, 60 \mathrm{~Hz})(\mathrm{S})$ elicits a prolonged increase in discharge rate. In contrast, a similar MFB stimulus train (S) produces a prolonged decrease in unit firing.

These three effects of MFB stimulation almost always occur together and thus provide a neurophysiological signature for MFB stimulation, especially since non-MFB placements in medial hypothalamus, zona incerta, cerebral peduncle, optic tract or meninges failed to produce this set of responses in 40 units tested. The finding that MFB and non-MFB stimulations have different neural effects is important in the present context as a means to identify MFB stimulation as the effective source of the unit responses cited.

In the anesthetized rat, medullary reticular ( $n$. gigantocellularis) stimulation at sites responding to peripheral noxious stimuli in each rat, has elicited, at latencies as low as $5.0 \mathrm{msec}$, excitation of 35 of 69 medial thalamus units. In the cerveau isolé rats, $7 \mathrm{~Hz}$ midbrain RET stimulation elicited responses in 50 of $60 \mathrm{DM}$ and PC units tested. The excitation in the $50-100 \mathrm{msec}$ poststimulus period is opposite to the typical MFB inhibition during the same poststimulus period (Fig. 2). This $7 \mathrm{~Hz}$ stimulation never elicited medial thalamic slowwave recruiting. In further contrast with MFB stimulation, increasing the frequency of RET stimulation increases the discharge rate of DM and PC units (Figs $1 F$ and 2). For 50 of 57 units tested, the discharge rate with $20 \mathrm{~Hz}$ midbrain RET stimulation was greater than with the $7 \mathrm{~Hz}$ stimulation. For 36 of the 50 units, the difference was statistically significant $(p<0.05)$. These 36 units had a prestimulus discharge rate of 17 spikes/sec; changing the RET stimulation frequency from 7
In the animals in which both the MFB and RET electrodes were accurately placed, it was possible to obtain an estimate of the degree to which MFB and RET effects converge on single medial thalamic units. It was found that stimulation of areas eliciting escape (RET) and self-stimulation (MFB) both affect 50 of $80(62 \%)$ units tested.

Stimulation $(20-60 \mathrm{~Hz})$ of the behaviorally opposite sites elicited opposite neural responses in the same unit: MFB evoked decrease and RET evoked increase in unit discharge. In $10 \mathrm{DM}$ and $\mathrm{PC}$ units with an average prestimulus discharge rate of 23 spikes/sec, increasing the frequency of MFB and RET stimulation from 7 to $20 \mathrm{~Hz}$ had opposite effects on the same unit. With MFB stimulation, the rate decreased from 40 to 14 spikes/sec; RET stimulation, however, increased the rate of the same units from 22 to 36 spikes/sec. Compared to the control rate (23 spikes/sec), the discharge rate with $20 \mathrm{~Hz}$ MFB stimulation is significantly lower $(p<0.02)$, and the $20 \mathrm{~Hz}$ RET rate is significantly greater than control $(p<0.006)$. One of these units is shown in Fig. 1. With brief, high frequency stimulus trains ( $60 \mathrm{~Hz}, 0.2 \mathrm{sec}$ duration), MFB evoked inhibition and RET evoked excitation of ten last several seconds after train termination (Fig. 3).

Several measures of neural response in the DM and PC nuclei have now been discussed in relation to stimulation of four anatomical regions: $\mathrm{MFB}$, hypothalamic regions outside the MFB fiber system, reticular formation, and parafasicularis. Of primary interest to this report are the 
differences between MFB and RET stimulus treatments which are summarized in Table 1. self-stimulation by placing lesions destroying the rost ral and catudal projections of the MFB. leaving MFB projedions to

TABLL: !

OPPOSITE EFFECTS OF MFB AND RET STIMULATION IN THE DM AND PC NUCIEI

\begin{tabular}{lll}
$\begin{array}{l}\text { 1. Poststimulus pattern } \\
\text { during } 7 \mathrm{~Hz} \text { stimulation }\end{array}$ & $\begin{array}{l}\text { MFB } \\
\text { short latency } \\
\text { excitation followed } \\
\text { by inhibition }\end{array}$ & $\begin{array}{l}\text { RET } \\
\text { mixed effects } \\
\text { followed by } \\
\text { excitation }\end{array}$ \\
$\begin{array}{l}\text { 2. Slow wave recruiting } \\
\text { during } 7 \mathrm{~Hz} \text { stimulation }\end{array}$ & yes & no \\
$\begin{array}{l}\text { 3. Rates with } 20 \mathrm{~Hz} \text { compared } \\
\text { to } 7 \mathrm{~Hz} \text { stimulation }\end{array}$ & decreased discharge \\
4. Posttrain $(60 \mathrm{~Hz}, 0.2 \mathrm{sec})$ & increased discharge \\
effects lasting sec & decreased discharge & increased discharge \\
\hline
\end{tabular}

\section{DISCUSSION}

The RET regions stimulated in this study have been shown to elicit escape behavior $[4,8,12]$. In two rats chronically implanted for escape testing prior to acute cerveau isolé unit recording, midbrain RET stimulation elicited both escape and excitation of DM and PC units with the same stimulation parameters. Two other midbrain sites failed both to elicit escape and to excite DM and PC units. All of the medullary RET sites used in the data analysis showed slow wave and multiple unit responses to subcutaneous foot shock at intensities eliciting flexion in the lightly anesthetized preparation. Stimulation of such a medullary RET site in an awake, behaving rat has elicited parallel increases in medial thalamic unit discharge rate and escape rate with increasing stimulus intensities [5].

Previous work has described responses of thalamic units to noxious cutaneous stimulation in rat [1] and squirrel monkey [3] and medullary reticular (n. gigantocellularis) unit responses to peripheral nerve stimulation in cat [4] and to subcutaneous foot shock in rat [8]. The present data from rat demonstrate an effect of medullary reticular stimulation on medial thalamic units. The midbrain RET sites in this study were located along the pathway from $n$. gigantocellularis to medial thalamus. In all of these studies. increased unit discharge is associated with aversive peripheral or intracranial stimulation.

The rewarding effects of MFB stimulation are well established [12]. The electrode placements outside the MFB in this study are not associated with self-stimulation behavior and fail to produce the unit responses elicited with MFB sites. Preliminary observations with chronically implanted, awake rats during self-stimulation indicate that rewarding MFB stimulation is associated with decreased medial thalamic unit discharge. It is reasonable to suppose that the MFB and RET stimuli used in this study are rewarding and aversive respectively. The particular effects of the higher frequency $(20$ or $60 \mathrm{~Hz}$ ) stimuli on unit discharge may, therefore, have significance regarding the increased behavioral effects of MFB and RET stimulation as the stimulus frequency is increased.

Efforts to identify efferent pathways essential for MFB medial thalamus intact, showed that the rostral and caudal projections were not essential for self-stimulation [13]. It is possible that the MFB-medial thalamus pathway involved in the unit responses reported here plays an important role in self-stimulation behavior.

In a study using similar rewarding and aversive brain stimulation in rat, it was found that hippocampal slow wave activity did not relate differentially to the motivationally opposite stimuli [14]. Another study has examined slow waves and unit activity in monkey hippocampus, amygdala, and piriform cortex while the animal was responding to aversive (electrical shock) and rewarding (food pellets) signals [6]. No clear evidence was found of different slow wave reactions to the shock and food signals, and reciprocally reacting units were exceptional $(2.5 \%$ of 234 units). These results contrast our finding reciprocal effects of rewarding and aversive brain stimulation on the majority of units in medial thalamic nuclei. The localization in medial thalamus of differential unit responses to behaviorally opposing stimuli is consistent with a number of studies utilizing lesion, stimulation, and recording techniques that have implicated this region in the interrelated phenomena of learning and motivation.

The basic theoretical problem behind this kind of study is that much brain unit activity is still a foreign language with reference to behaviorally defined terminology such as reward and pain. Analysis geared to detect internal consistencies, however, might be expected to decipher related neuronal languages. The basic strategy of the present research, then, involves exploration for convergence of effects on single neurons. The unit analysis of motivational stimuli summarized above, for example, may provide a means to ascribe a behavioral meaning to firing rate changes which were not previously understood. Because of the convergence of opposite effects of stimuli that are behaviorally opposite, two languages, behavioral and neuronal, can be logically related and inferences made. Hence, the finding of reciprocal effects in medial thalamus not only implicates this region in the integration of reward and pain mechanisms, but also provides clues about the neural representation of reinforcing stimuli at this juncture in the brain. 


\section{REFERENCES}

1. Angel, A. The effect of peripheral stimulation on units located in the thalamic reticular nuclei. J. Physiol., Lond. 171: 42-60, 1964.

2. Brodel, A. and G. F. Rossi. Ascending fibers in brain stem reticular formation of cat. Archs Neurol. Psychiat. 74: 68-87, 1955.

3. Casey, K. L. Unit analysis of nociceptive mechanisms in the thalamus of the awake squirrel monkey. J. Neurophysiol. 29: $727-750,1966$.

4. Casey, K. L. Somatosensory responses of bulboreticular units in awake cat: relation to escape producing stimuli. Science 173: $77-80,1971$.

5. Casey, K. L. and J. J. Keene. Unit analysis of the effects of motivating stimuli in the awake animal: pain and self-stimulation. In: Brain Unit Activity During Behavior, edited by M. I. Phillips, Springfield, Ill: Charles C. Thomas, 1973.

6. Fuster, J. M. and A. A. Uyeda. Reactivity of limbic neurons of the monkey to appetitive and aversive signals. Electroenceph. clin. Neurophysiology 30: 281-293, 1971.

7. Goodman, S. J. and P. E. G. Mann. Reticular and thalamic multiple unit activity during wakefulness, sleep and anesthesia. Expl Neurol. 19: 11-24, 1967.

8. Keene, J. J. and K. L. Casey. Excitatory connection from lateral hypothalamic self-stimulation sites to escape sites in medullary reticular formation. Expl Neurol. 28: 155-166, 1970 .

9. Krupp, P. and M. Monnier. The unspecific intralaminary modulating system of the thalamus. Int. Rev. Neurobiol. 9: $45-94,1966$
10. Millhouse, O. E. A Golgi study of the descending medial forebrain bundle. Brain Res. 15: 341 - 363, 1969.

11. Nauta, W. J. H. and H. Kuypers. Some ascending pathways in the brain stem reticular formation. In: Reticular Formation of the Brain, edited by H. H. Jasper and L. Proctor. Boston: Little, Brown, and Co., 1958.

12. Olds, J. and M. E. Olds. Approach-avoidance analysis of rat diencephalon. J. comp. Neurol. 120: 259-295, 1963.

13. Olds, M. E. and J. Olds. Effects of lesions in medial forebrain bundle on self-stimulation behavior. Am. J. Physiol. 217: 1252-1264, 1969.

14. Pond, F. J. and J. S. Schwartzbaum. Hippocampal electrical activity evoked by rewarding and aversive brain stimulation in rats. Communs Behav. Biol. 5: 89-103, 1970.

15. Purpura, D. P. Role of synaptic inhibition in synchronization of thalamocortical activity. Prog. Brain Res. 22: 107-122, 1968.

16. Purpura, D. P. and B. Cohen. Intracellular recording from thalamic neurons during recruiting responses. $J$. Neurophysiol. 25: $621-635,1962$.

17. Scheibel, M. E. and A. B. Scheibel. Anatomical basis of attention mechanisms in vertebrate brains. In: The Neurosciences, edited by G. C. Quarton, T. Melnechuk, and F. O. Schmitt. New York: Rockefeller University Press, 1967.

18. Spears, R., G. Smith and K. L. Casey. A pulse height discriminator and post-stimulus histogram system using integrated circuits. Physiol. Behav. 5: 1327-1329, 1970. 